\title{
Assessment of Pump's Performance in Water Supply Systems - Data Collected from Multiple Case Studies
}

\author{
By Pedro Cardoso ${ }^{1}$, António Santos ${ }^{1}$, Ricardo Rato ${ }^{1}$, Marco Estrela ${ }^{1}$
}

\begin{abstract}
This paper reports the evaluation of pump's efficiencies and its optimization potential, in three water supply systems. The study surveyed 65 pumps groups, from 24 pumping stations, between 5 to 350 $\mathrm{kW}$ of absorbed power, with flow rates from 25 to $1500 \mathrm{~m} 3 / \mathrm{h}$. The performance of the pumps, was assessed by testing each pump group in different operational conditions. It was quantified, for each pump group, the specific consumption $(\mathrm{kWh} / \mathrm{m} 3)$ and cost $(€ / \mathrm{m} 3)$ as well as the difference between the optimum efficiency point, for the specific net head of each installation, and their actual operating point. The identified energy inefficiencies and proposed corrective measures for each pump group were compiled in order to improve their efficiency. Most problems identified are oversized groups, valve problems and inadequate operational working points. On average the surveyed pump's efficiencies were 10 percentage points below their reference values. In order to reduce the gap several improvement measures were proposed, such as the refurbishment of the pumps, impeller adjustments, variable speed drive installation and the extension of the working periods with lower frequency regimes, where high efficiencies were identified. The implementation of these improvement measures has an energy saving potential of $331 \mathrm{MWh} /$ year, which means 27.000 $€ /$ year.
\end{abstract}

\section{Introduction}

This study aims to assess the actual operational conditions and performance of the pump groups, from three water supply systems in Portugal. The study surveyed 65 pumps groups, from 24 pumping stations, between 5 to $350 \mathrm{~kW}$ of absorbed power, with flow rates from 25 to $1500 \mathrm{~m}^{3} / \mathrm{h}$. For each pump group were collected relevant parameters for its characterisation and identified potential energy inefficiencies in order to propose improvement measures to correct them.

Pumps are widely used in almost every economic sector, providing fluid transport to cooling and heating, lubrication, industrial processing, motive force in hydraulic systems or simply to water transportation. Pumping systems account for nearly $20 \%$ of the world's electrical energy demand and range from $25-50 \%$ of the energy usage in certain industrial plant operations (Hydraulic Institute, Europump et al, 2001).

In the water sector, pumping water entails electrical energy consumption which currently corresponds to a significant part of the total electricity consumption in distribution systems (IMechE, 2004.), it could reach 90\% (Grundfos, 2004). In the Portuguese water utility company, the energy costs represent nearly $60 \%$, and maintenance costs are close to $20 \%$ of all operational costs, excluding personal costs (Mendes, 2016). In 2015 the drinking water supply and distribution systems of Portugal demanded a consumption of 
electric energy of $406 \mathrm{GWh}$, which corresponds to $0,86 \%$ of all electric energy consumed in Portugal (Mendes, 2016). Therefore, reliability and efficiency of the pump groups is extremely important.

Many studies have been carried out aiming at the optimal pump scheduling (Jowitt \& Germanopoulos, 1992) (McCormick \& Powell, 2003) (Nitivattananon et al., 1996), taking into account the fact that energy costs can be frequently reduced by consuming electricity in off-peak hours. However, part of the energy that is consumed by the pump groups is associated to the inefficiencies of the equipment and to operating pump groups outside their best-efficiency points. Pump performance also decreases after prolonged and heavy duty service life as a result of erosion, corrosion, wear and cavitation. Much of the pump wear occurs in the first years of operation and tends to level out after the first 10 years. The overall drop in efficiency for an inadequately maintained pump can be $5 \%$ in the first five years of operation and up to 15\% in the first 10 years (IMechE, 1989). Part of this loss of efficiency is due to degradation of the impeller/casing wear rings. The degradation rate tends to be much higher in pumps operating far from the bestefficiency point due to increased shaft deflection. Most of the loss in efficiency will normally be caused by a build-up of corrosion products in cast iron casings. This occurs in practically all pumps working with clean cool water. Periodically maintaining the pump can return its efficiency to a similar level of a new pump. (UK Department of the Environment, 1998).

These inefficiencies have a direct economic impact in water utilities operating costs due to high energy consumption. For that reason, most recent studies on energy efficiency optimization in water supply systems are now including pumps efficiency (Bolognesi et al., 2014). Still, there is a lack of studies focusing on the efficiency decrease in pumps of water supply systems and its relation to operating time and conditions. Research efforts in technological solutions, which increase energy efficiency of water supply systems, are now a priority (Ramos et al, 2012). In this study were surveyed 24 pumping stations and collected for each the following data (per pump group): flow rate, net head, absorbed power, efficiency (hydraulic and electric) and were obtained, for all pumping stations, the hydraulic systems curve (net head vs flow). One of the objectives was to identify the actual operational conditions of the pump groups and in addition, to find opportunities for providing solutions to reduce the energy expenses of inefficient pump groups. Solutions could namely be upgrades with high efficiency pumps and motors, reduction of impeller diameter for oversized pumps, pumps refurbishment with internal ceramic coating and replacement of wearing parts, installation of variable speed drives and adjustments in pumping operational procedures, which don't need any additional investment and have immediate cost reductions impact.

\section{Methodology}

In order to collect the relevant data for the characterization of each of the 24 pumping station's groups, they had to be respectively submitted to different operational conditions. The analysis was performed group by group, through different operational conditions: one group operating (though different frequency regimes, if it has variable speed drive); more than one group operating. 
If the groups were equipped with variable speed drive, only the analysed group would be tested through different frequency regimes. Whenever was possible the groups with variable speed drive were tested through 4 different frequency regimes, between $50 \mathrm{~Hz}$ and its lowest operational frequency. When a group was operating with one or more groups, at the same time, they were operated at their nominal frequency. These tests allowed an evaluation of the efficiency of the groups under a range of operating conditions and showed how the groups react to discharge variations. Additionally, the difference between the optimum efficiency point for the net head of each installation and their actual operating point was calculated.

An energy analyser was installed on the electric frame that feeds the analysed group. Pressure was measured at the upstream and downstream of the pump groups using digital manometers. Flow was measured using an ultrasonic flow meter. Each pump was tested for the current operating conditions and for different discharges. For each operating condition, the pumps worked continuously until reaching a steady state. Then the following data was collected: upstream and downstream Pressure of the analysed group; Net Head of the site; Flow of the analysed group and total groups combined; Electric and Hydraulic Power of the analysed group; Efficiency of the analysed pump, motor, variable speed drive; Specific consumption of the analysed group $\left[\mathrm{kWh} / \mathrm{m}^{3}\right]$ and $\left[€ / \mathrm{m}^{3}\right]$.

From the 24 surveyed pumping stations, two different situations were identified. In the most usual situation, it was possible to install a pressure sensor on the influent pipe of the analysed group. In this situation it is possible to collect directly the influent pressure value, without any calculations.

In some pumping stations was not possible to directly measure the Pressure on the influent because the influent pipe did not have any fitting to install the pressure sensor or because the groups were located immediately above a storage tank or dam, which limited the accessibility to work in the influent duct. In this case, the value of the Pressure difference between the influent and the effluent was theoretically calculated. First was measured the difference of height between the analysed pump and the surface water level in the storage tank or dam and also the dynamic pressure difference between the surface of water in the storage tank and at effluent conditions. With this data it is possible to calculate the value of the net head, the hydraulic power provided by the analysed group and to evaluate its efficiency. In all measured pump groups, the diameter of the influent and the effluent were the same.

When was not possible to measure the influent pressure in situ, was used the following equation:

$H=\frac{\left(P_{e} * 100000\right)}{\rho g}+\frac{\left(\frac{Q / 3600}{\pi\left(\frac{\emptyset}{2}\right)^{2}}\right)^{2}}{2 g}+\Delta \mathrm{Z}$

Where:

$\mathrm{H}=$ Net Head $[\mathrm{m}]$;

$\mathrm{P}_{\mathrm{e}}=$ Effluent static pressure [bar];

$\mathrm{Q}=$ Pump Flow $\left[\mathrm{m}^{3} / \mathrm{h}\right]$;

$\Delta Z=$ Difference of height between the analysed pump and the surface water level [m]; 
$\rho=$ Water density $-999\left[\mathrm{Kg} / \mathrm{m}^{3}\right]$;

$\mathrm{g}=$ Gravity acceleration $-9,807\left[\mathrm{~m} / \mathrm{s}^{2}\right]$.

When was possible to measure the influent pressure in situ, was used the following equation:

$H=\frac{\left(\left(P_{e}-P_{i}\right) * 100000\right)}{\rho g}+\Delta \mathrm{Z} \quad$ (eq.2)

Where:

$\mathrm{H}=$ Net Head $[\mathrm{m}]$;

$\mathrm{P}_{\mathrm{e}}=$ Effluent static pressure [bar];

$\mathrm{P}_{\mathrm{i}}=$ Influent static pressure [bar];

$\Delta \mathrm{Z}=$ Difference of height between the installed pressure meters $[\mathrm{m}]$;

$\rho=$ Water density $-999\left[\mathrm{Kg} / \mathrm{m}^{3}\right]$;

$\mathrm{g}=$ Gravity acceleration $-9,807\left[\mathrm{~m} / \mathrm{s}^{2}\right]$.

For all situation where used the following equations:

$\Delta P_{b}=H * \rho g * 0,00001 \quad$ (eq.3)

$P_{h}=\frac{\left.Q * \Delta P_{b} * 100\right)}{3600} \quad$ (eq.4)

$\mu_{g}=\frac{P_{h}}{P_{a b}} \quad$ (eq.5)

$\mu_{b}=\frac{\mu_{g}}{\mu_{v^{*}} \mu_{m}} \quad$ (eq.6)

Where:

$\mathrm{H}=$ Net Head $[\mathrm{m}]$;

$\Delta P_{b}=$ Difference between effluent and influent pressure, in the pump [bar];

$\rho=$ Water density $-999\left[\mathrm{Kg} / \mathrm{m}^{3}\right]$;

$\mathrm{g}=$ Gravity acceleration $-9,807\left[\mathrm{~m} / \mathrm{s}^{2}\right]$.

$\mathrm{Q}=$ Pump Flow $\left[\mathrm{m}^{3} / \mathrm{h}\right]$

$\mathrm{P}_{\mathrm{h}}=$ Hydraulic Power $[\mathrm{kW}]$;

$P_{a b}=$ Absorbed Power $[\mathrm{kW}]$;

$\mu_{g}=$ Global Efficiency [\%]

$\mu_{b}=$ Pump Efficiency [\%]

$\mu_{v}=$ Variable speed drive Efficiency [\%];

$\mu_{m}=$ Motor Efficiency [\%]

With the gap between the actual value and the reference value for each pump efficiency, it is possible to evaluate the necessity for the implementation of improvement measures for the analysed group. If the efficiency gap was larger than $10 \%$ were proposed improvement measures, with quantification of costs and savings. The specific cost, for each pumping station, was based on its energy cost from a typical year (it was considered the year of 2014).

\section{Results}

\subsection{Demonstration systems characterization}

The in-situ surveys resulted in the characterization of water circuits and collection of specification data from the majority of pumps and auxiliary equipment. In 
addition to the technical information collected, the energy consumption and flow metering allowed the pumps working point characterization, Figure 1 and the specific consumption calculation, Figure 2 and Figure 3.

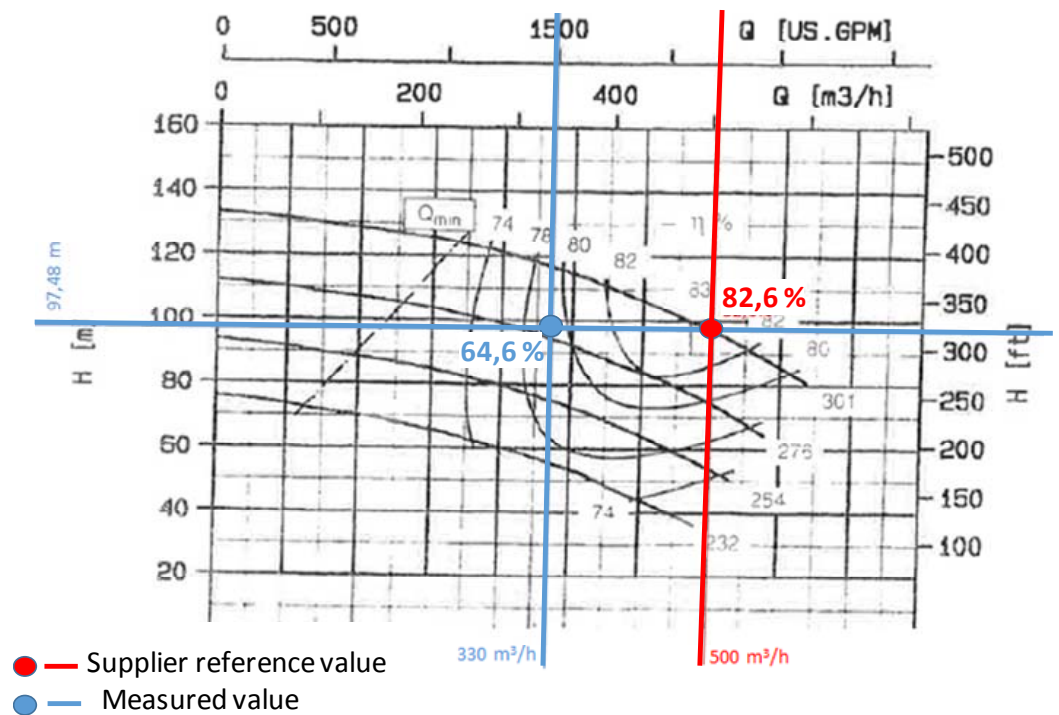

Figure 1 - Example of pump Curve: pump working point in the pump curve

From the pump curve it was possible to establish the difference between the expected efficiency and the actual pump working point. In most cases, this difference shows that the pump performance is actually below than their reference values.

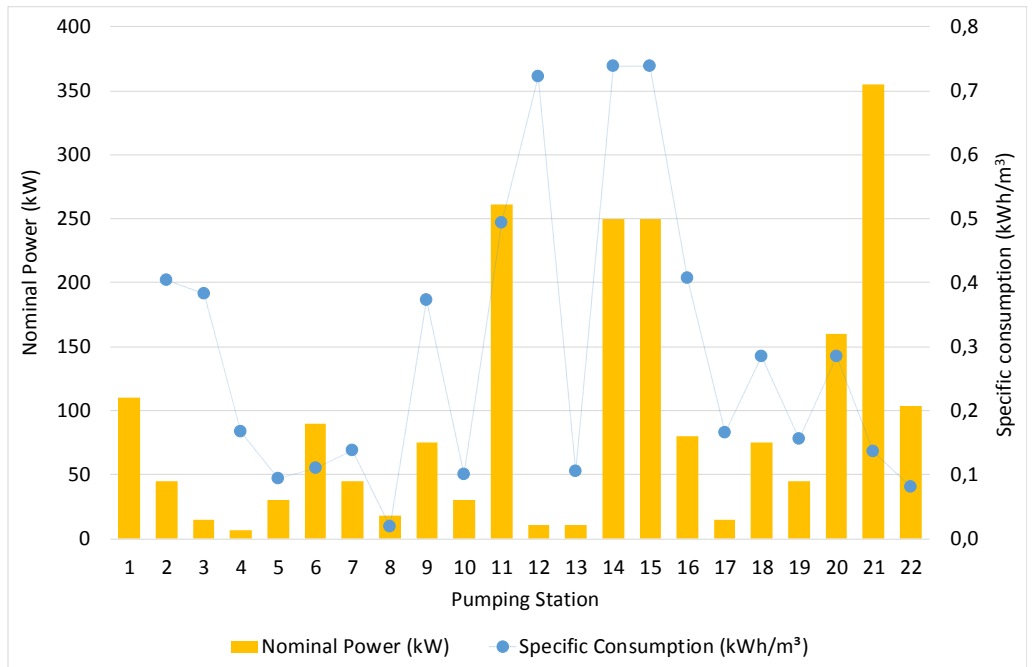


Figure 2 - Installed capacity and specific energy consumption (in two pumping stations was not possible to identify the nominal power of the pumps)

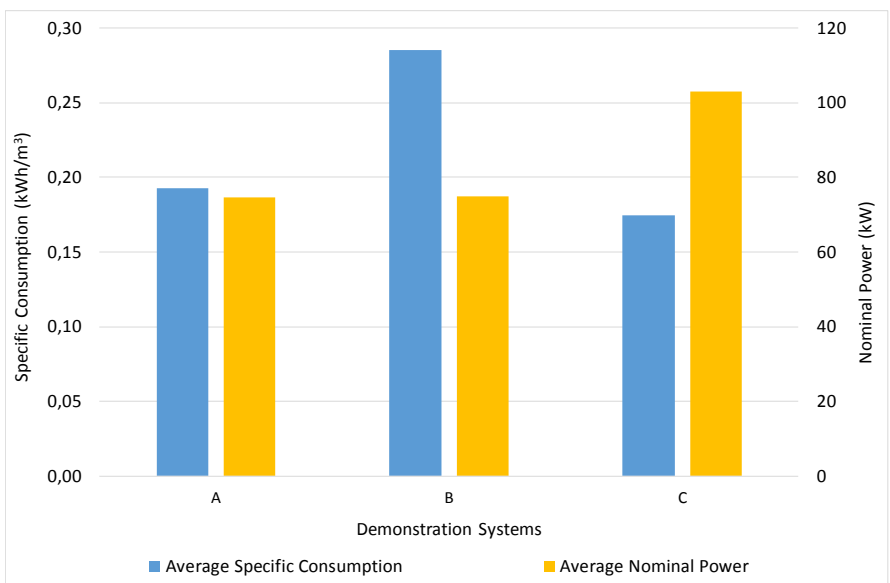

Figure 3-Average specific consumption and pumps absorbed power of the three demonstration systems

The study surveyed 65 groups composed by centrifugal horizontal or vertical pumps, between 5 to $350 \mathrm{~kW}$ of absorbed power, with flow rates from 25 to $1500 \mathrm{~m}^{3} / \mathrm{h}$. These groups have on average a specific energy consumption of $0,2 \mathrm{kWh} / \mathrm{m}^{3}$. It is not possible to correlate the installed capacity and the specific consumption of the groups (as shown in Figure 2). This is due to the impact of several parameters such as net head of the installation and the mechanical conditions of the equipment in the entire system performance, which vary significantly from each installation.

During the surveys were identified energy inefficiencies in the demonstration systems, namely oversized systems, valve obstructions and non-optimized operational regimes. As a result, efficiency levels measured were significantly lower than the ones provided by the manufacturer or supplier. This situation is well portrayed by Figure 4 and Figure 5 where it is possible to identify the efficiency gaps. These gaps have an average value of 10 percentage points. Figure 4 shows the pump's nominal power and the respective efficiency gap between their measured and reference values, in percentage points. Figure 5 shows occurrence distribution of that efficiency gap. 


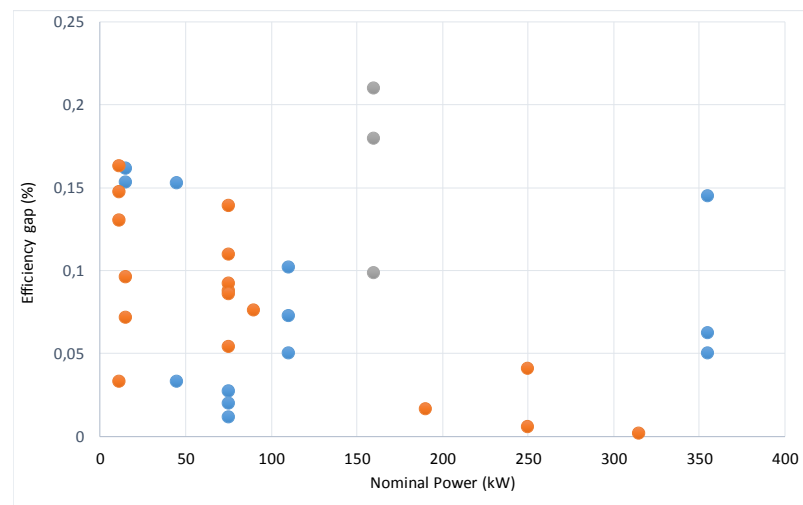

- $\mathrm{A} \quad \bullet \mathrm{B} \quad \bullet \mathrm{C}$

Figure 4 - Efficiency gap between measured values and their reference values within the three demonstration systems

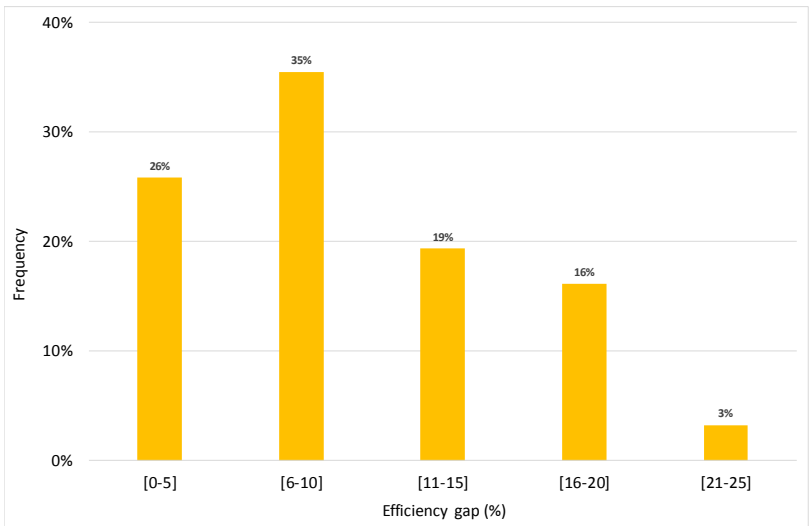

Figure 5 - Efficiency gap intervals frequency

Regarding to equipment maintenance and number of hours worked per group, due to the lack of data available, it is not possible to establish a correlation between the number of hours worked and the efficiency of the pumps efficiency, as shown in Figure 6.

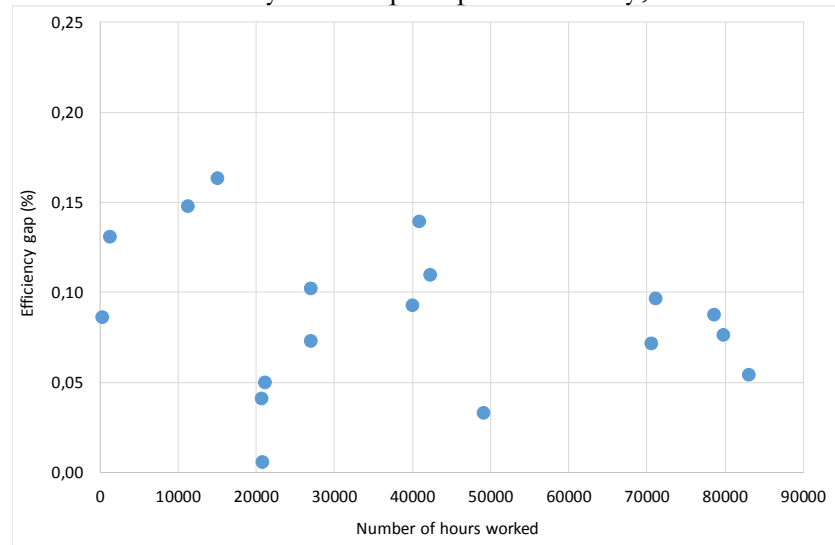

Figure 6 - Relation between working time and efficiency decrease to the pump reference values 


\subsection{Improvement measures}

The improvement potential identified by the surveys, from the 24 pumping stations, resulted in an improvement measures list divided in 4 main categories, presented in Figure 7, which included the refurbishment of the pumps, motor replacement, component correction, as impeller trimming and operational changes. The refurbishment consists in applying an internal ceramic coating which reduces friction factor by more than 40\% (U.S. Department of Energy et al., 2006) and corrosion. Additionally, it consists in bearing and wear-ring replacement and the impeller adjustment, replacing it for a smaller one or reducing the outside diameter. Variable speed drive, e.g. VFD, variable frequency drive, suggested for 13 pumping stations, improving the operating cost and reliability of the systems. Moreover, it also allows matching flow and pressure requirements closer to system needs, allowing the extension of the working periods with lower frequency regimes with more groups working at the same time, where high efficiencies were identified. For the same flow, better efficiencies and specific consumptions were achieved when the groups were operating together, because the hydraulic power is improved and the electric power consumption of each group decreases. The savings generated by this measure are predicted to be significant, at least $10 \%$. During the survey was noted that one valve, after one group was choked, due to space limitation for its complete opening. The valve was reassembled and this situation was corrected during the survey. The motor replacement by a higher-class motor was suggested for the pump groups that have a standard class motor with lower performances and in other cases seems to be oversized.

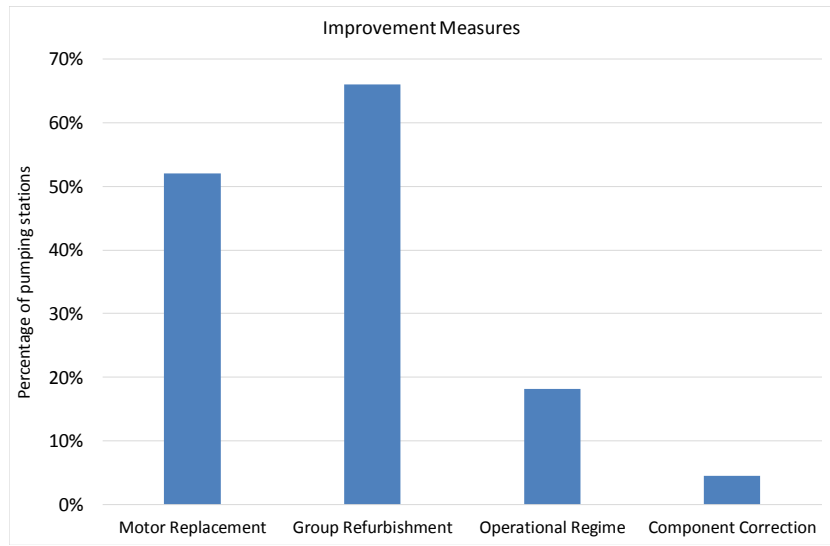

Figure 7 - Percentage of pumping stations with potential of efficiency improvement

From the 65 pump groups assessed it was suggested improvement measures for 42 groups and quantified the energy and economic savings for 30 groups, as shown in Figure 8. It was not proposed any improvement measure for the rest of the groups due to the lack of provided data or because further studies are needed and were out of the scope of these surveys. Therefore, there is an undoubted potential for improvement measures, which were not quantified yet. 


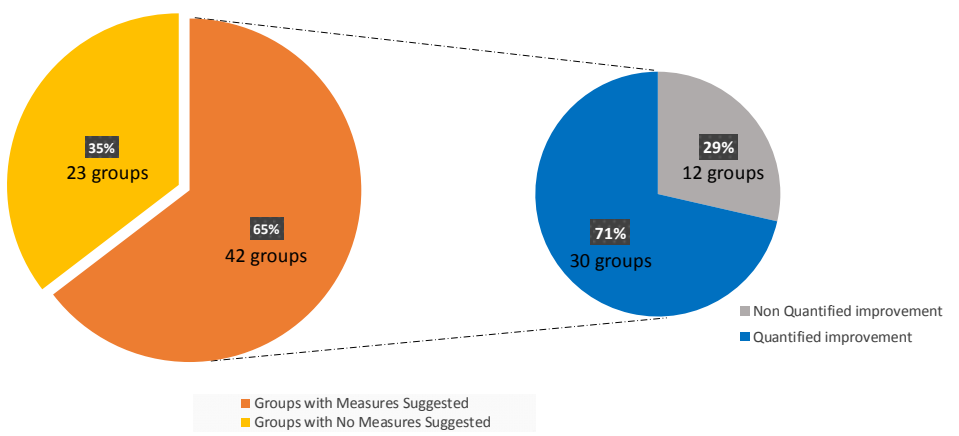

Figure 8 - Percentage of pump groups with suggested improvement measures and the number of quantified saving measures.

\section{Conclusions}

The benefit of the improvement measure implementation is available for consultation on Table 1. The total investment required to implement the measures at the identified 30 groups is 54.440 Euros, with an estimated impact in energy savings around $3.110 .000 \mathrm{kWh}$ per year, which results in an average payback period of less than 3,5 years, taking into account the electricity tariffs charged in Portugal. As shown in Figure 9.

Table 1- Benefits of proposes measures

\begin{tabular}{|c|c|c|c|c|c|c|c|c|}
\hline \multirow{3}{*}{$\begin{array}{c}\text { Demonstration } \\
\text { System }\end{array}$} & \multirow{3}{*}{$\begin{array}{l}\text { Pumping } \\
\text { station }\end{array}$} & \multirow{3}{*}{$\begin{array}{l}\text { Number of } \\
\text { Groups }\end{array}$} & \multirow{2}{*}{$\begin{array}{c}\text { Annual } \\
\begin{array}{c}\text { Operational } \\
\text { Requirements } \\
\text { (per pump) }\end{array} \\
\text { Water Volume } \\
\end{array}$} & \multicolumn{2}{|c|}{ Current Situation } & \multicolumn{2}{|c|}{ Proposed Situation } & \multirow{3}{*}{$\begin{array}{c}\begin{array}{c}\text { Annual } \\
\text { Savings }\end{array} \\
€\end{array}$} \\
\hline & & & & $\eta_{\text {pump }}$ & Energy & $n_{\text {pump }}$ & Energy & \\
\hline & & & [ $\mathrm{m}^{3} /$ year/group] & [\%] & [kWh/year/group] & [\%] & [kWh/year/group] & \\
\hline \multirow{6}{*}{ A } & 1 & 1 & 3321900 & $71 \%$ & 460241 & $76 \%$ & 429883 & 2732 \\
\hline & 2 & 3 & 244844 & $69 \%$ & 48505 & $74 \%$ & 45404 & 855 \\
\hline & 3 & 2 & 269652 & $54 \%$ & 116309 & $59 \%$ & 106475 & 1901 \\
\hline & 4 & 3 & 970459 & $47 \%$ & 111373 & $52 \%$ & 100648 & 3086 \\
\hline & 5 & 3 & 498985 & $38 \%$ & 63089 & $42 \%$ & 55818 & 2092 \\
\hline & 6 & 2 & 548344 & $69 \%$ & 104681 & $42 \%$ & 92649 & 2048 \\
\hline \multirow{5}{*}{ B } & 7 & 1 & 206404 & $55 \%$ & 219954 & $60 \%$ & 201624 & 1595 \\
\hline & 8 & 2 & 206404 & $59 \%$ & 27537 & $64 \%$ & 25531 & 353 \\
\hline & 9 & 2 & 426451 & $60 \%$ & 257520 & $63 \%$ & 238019 & 1588 \\
\hline & 10 & 2 & 206877 & $58 \%$ & 43076 & $62 \%$ & 40316 & 328 \\
\hline & 11 & 4 & 661016 & $69 \%$ & 172742 & $72 \%$ & 164841 & 1010 \\
\hline \multirow{2}{*}{ C } & 12 & 2 & 684338 & $44 \%$ & 151359 & $49 \%$ & 136039 & 2039 \\
\hline & 13 & 3 & 1368677 & $66 \%$ & 570735 & $71 \%$ & 540847 & 7263 \\
\hline & & & & & & & Total & 26889 \\
\hline
\end{tabular}




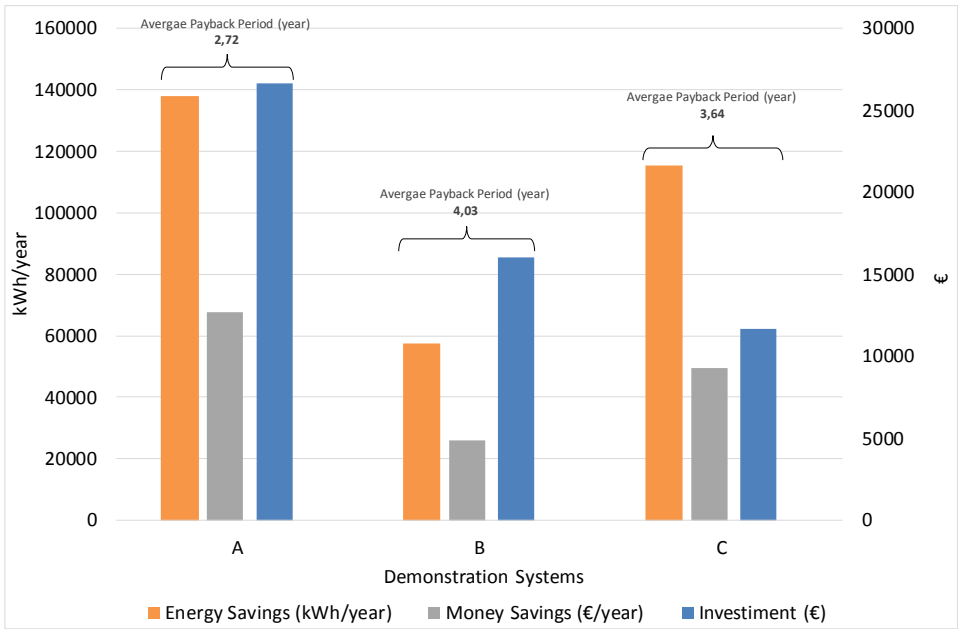

Figure 9 - Energy Savings, Financial Savings and payback period

From the 24 pumping station surveyed, were proposed improvements for 18 of them, and were quantified improvement measures for 13 of them in a total of 30 pumps. Additionally, a change in the operation regime is suggested, specifically the use of variable speed drives at lower frequencies where high efficiencies were identified. Furthermore, it allows matching working time with favourable tariff period. Pump scheduling is one of the most important tasks of the operation of a water distribution system as it represents the major part of its operating costs (Bagirov et al, 2012). The total annual savings resulting from the implementation of the identified improvement measures, at these 13 pumping stations, are $311.129,53 \mathrm{kWh} /$ year which represent $26.888,76 €$ of savings per year.

\section{Acknowledgements}

This work is funded by the Portuguese Foundation for Science and technology, in the scope of the project UID/EMS/00712/2013.

\section{References}

Bagirov, A. M., Barton, A. F., \& Mala-Jetmarova, H. A. (2012). An algorithm for minimization of pumping costs in water distribution systems using a novel approach to pump scheduling. Mathematical Computer Modelling, 57, 873-886.

Bolognesi, A., Bragalli, C., Lenzi, C., \& Artina, S. (2014). Energy Efficiency Optimization in Water Distribution Systems. Procedia Engineering, pp. 70, 181-190.

Grundfos. (2004). Pump Handbook. Management A/S Grundfos.

Hydraulic Institute, Europump, US Department of Energy's Office of Industrial Technologies. (2001). Pump Life Cycle Costs: A Guide to LCC Analysis for Pumping Systems. DOE/GO-102001-1190.

IMechE - Institution of Mechanical Engineers. (1989). Pumping Cost Savings in the Water Supply Industry . Papers Presented at a Seminar Organised by the Fluid Machinery Committee of the Power Industries Division.

IMechE. (2004.). Centrifugal Pumps: State of the Art and New Opportunities, first. ed. - Institution of Mechanical Engineers. Bury St Edmunds and London, UK.: John Wiley \& Sons. 
Jowitt, P., \& Germanopoulos, G. (1992). Optimal Pump Scheduling in Water-Supply Networks. J. Water Resour. Plann. Manage., pp. 118, 406-422.

McCormick, G., \& Powell, R. (2003). Optimal Pump Scheduling in Water Supply Systems with Maximum Demand Charges. J. Water Resour. Plann. Manage., pp. 129, 372-379.

Mendes, J. N. (2016). Inovação e I\&D no Grupo AdP. Workshop LIFE Smart Water Supply System. Oeiras.

Nitivattananon, V., Sadowski, E., \& Quimpo, R. (1996). Optimization of Water Supply System Operation. J. Water Resour. Plann. Manage., pp. 122, 374-384.

Ramos, H., Vieira, F., \& Covas, D. (2012). Energy efficiency in a water supply system: Energy consumption and CO2 emission. Water Science and Engineering (3), 331-340.

U.S. Department of Energy; Industrial Technologies Program (ITP) \& Hydraulic Institute . (2006). Improving Pumping System Performance: A Sourcebook for Industry .

UK Department of the Environment, Transport and the Regions. (1998). Energy savings in industrial water pumping systems - Good pracatice guide - 249. 